\title{
Determination of LC50 of Diazinon toxin and linear anionic detergents on Rutilus frisii kutum
}

\author{
A. Tehranifard ${ }^{1}$, M. Fazeli ${ }^{2}$ \& J. Yarabbi ${ }^{3}$ \\ ${ }^{I}$ Department of Marine Biology, Islamic Azad University of Lahijan, Iran \\ ${ }^{2}$ Tarbiatmodares University, Iran \\ ${ }^{3}$ Adamson University, Philippines
}

\begin{abstract}
Diazinon is a pesticide that is commonly used in the rice fields of northern Iran The harmful effect of Diazinon and two anionic detergents were determined on Rutilus frisii kutum, individually and together on a laboratory scale. Fish were adapted to laboratory circumstances, distributed species wise in 500 litre tanks. Experiments were performed according to the TCR standard procedures. The LC50- $96 \mathrm{~h}$ was $0.34 \mathrm{mg} / \mathrm{l}$ for Diazinon. The LC50- $96 \mathrm{~h}$ in same species fingerlings were 4.69 and $12.24 \mathrm{mg} / \mathrm{l}$ under liquid and powder detergents, respectively. The LC50- $96 \mathrm{~h}$ were 7.27 and $0.9 \mathrm{mg} / \mathrm{l}$ for a mixture of Diazinon and liquid detergent and a mixture of Diazinon and powder detergent, respectively. The result showed that the toxicity of the mixture of Diazinon and powder detergent was greater than other mixtures. Generally, the detergent concentration toxicity rate (LC50- $96 \mathrm{~h}$ ) in the ecosystem is less than the laboratory scale, but detergent can mix with some chemicals in the ecosystem and become stronger. The mortality rate will increase under this condition.

Keywords: LC50- 96 h, acute toxicity, anionic detergent, Diazinon, Rutilus frisii kutum.
\end{abstract}

\section{Introduction}

Today, pesticides are used for many different purposes, such as agriculture, human and animal health protection, pest control in forest and aquatic environments, and the protection of buildings and other structures. The uses of pesticides are increasing because the target pests become stronger, and therefore, large amounts of detergents contaminate soil and water annually (Young [5]). Pesticides sources in the environment include those resulting from direct pesticide application for a 
specific purpose, such as those used for weed and insect control in aquatic environments, and those entering indirectly from spray drift, atmospheric precipitation runoff and erosion from agricultural lands, effluent discharges from sewers and factories, accidental spills and volatilization. The quantity of a pesticide moving with runoff and sediment to an aquatic environment depends on many factors. These include topography, intensity and duration of runoff or irrigation, soil erodibility, land management and cropping practices [2].

Pollution magnitude varies with aquatic environment properties, such as surface area and depth, and hydraulic characteristics. However, the highest pesticide residues are in rivers; lower residues occur in estuaries and the lowest are in the oceans. Pollution magnitude in lakes and reservoirs depends on their proximity to an agricultural or industrial area (Tamim and Weigmann [2]). Biological communities are sensitive to their chemical environment, although the degree of sensitivity varies among species and communities. The use of pesticides in Iranian agriculture is common, but from an environmental protection of point of view it is not controlled as effectively as it ought to be. If the fields are too near to the aquatic ecosystem the pesticides may be washed out from the treated soil and pollute the aquatic ecosystem by runoff. This is particularly dangerous in rice fields. In this case the water is directly tested and in connection with rivers or standing waters [3].

There are approximately 600,000 hectares of rice fields, and houses near the rivers use detergents daily in the north of Iran. There is no ecotoxicological data about the harmful effect of pesticides and detergents individually or in mixed concentrations on aquatic organisms in Iran.

For this reason we consider that the investigation of some special Anionic detergents and Diazinon are important. This is the first ecotoxicological effects investigation on fish in Iran.

This research should correctly imply an at least approximate equivalence of fish species in their susceptibility to chemical compounds under the conditions described in the official guidelines (OECD [1]).

\section{Material and methods}

\subsection{Diazinon}

Is commonly used in rice fields of northern Iran were bought from pesticides shop in Bandar Anzali. Active ingredient: EC 60\% (Diazinon)

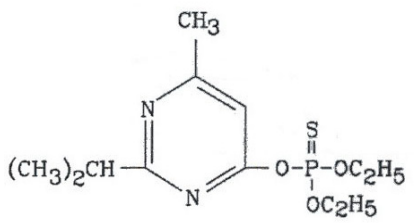

Figure 1: Chemical formula. Water solubility: in water at room temperature $40 \mathrm{mg} / \mathrm{l}$. Toxicity: tech (rat): Oral LD50 300-400 mg/kg. $3.5 \mathrm{mg} / \mathrm{L}$ (4hr). Rabbit. inhalation: LC50. 


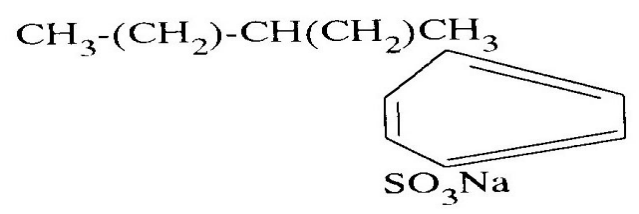

Figure 2: $\quad$ L.A.S formula.

\subsection{Test organism}

Rutilus frisii kutum (White fish), was bought from Shahid Ansari fish culture and propagation station.

At the Gilan Fisheries Research Center, which was given the task of studying the effect of pesticide and detergents on fish were performed in similar equipments. The temperature of the room was regulated to $25 \pm 2^{\circ} \mathrm{C}$. There were two light sources of $70 \times 100 \mathrm{~cm}$ ( $20 \mathrm{w}$ and $60 \mathrm{~cm}$ long). Duration of illumination (14h/day) was automatically regulated [4].

Fish were adapted to laboratory circumstances distributed species wise in 500 litre tanks. Experiments for determining Diazinon, 24-hr, 48-hr, 72-hr, 96-hr LC10, LC50 and LC90 were performed according to the TCR standard procedures (TCR [4]).

Different test concentrations plus a control were used. 1-2 g fingerling fish (Rutilus frisii kutum) was used for each concentration series. A total of these replicates were carried out for each one. Ten fingerling fish (1-2g weight) were placed in a 30 litre aquarium containing 20 litres tap water for each test concentration and control. Pesticides stock solution was prepared with distilled water and four concentrations of them plus a control were chosen. Each treatment consisted of three replicates. During of the test (4 day) the organisms were not fed and the medium was not renewed during the bioassay. Observations were made at each 24-h and the mortality results recorded. Control survival was always $100 \%$. LC10, LC50, LC90, (the concentration of the toxicant that reduced the survival rate to $10 \%, 50 \%$ and $90 \%$ ) were calculated using linear regression analysis [5].

\section{Results}

\subsection{Influences of the investigated pesticide Diazinon on Rutilus frisii kutum}

According to three different experiments with various concentrations of Diazinon on Rutilus frisii kutum ( 0.3 to $5 \mathrm{mg} / \mathrm{l})$ in comparison with the control, mortality was increased especially with the high concentration. LC50-96hr was $0.34 \mathrm{mg} / \mathrm{l}$.

The results are summarized in Table 1 and Figure 3. 
Table 1: $\quad$ Effect of Diazinon on Rutilus frisii kutum.

\begin{tabular}{|c|c|c|c|c|c|}
\hline Diazinon & $\begin{array}{c}\text { Lethal concentration } \\
\text { (p.p.m) }\end{array}$ & $24 \mathrm{hr}$ & $48 \mathrm{hr}$ & $72 \mathrm{hr}$ & $96 \mathrm{hr}$ \\
\hline Rutilus frisii kutum & LC10 & 0.24 & 0.14 & 0.18 & 0.14 \\
& LC50 & 1.7 & 0.08 & 0.49 & 0.34 \\
& LC90 & 12.057 & 4.954 & 1.34 & 0.8 \\
\hline
\end{tabular}

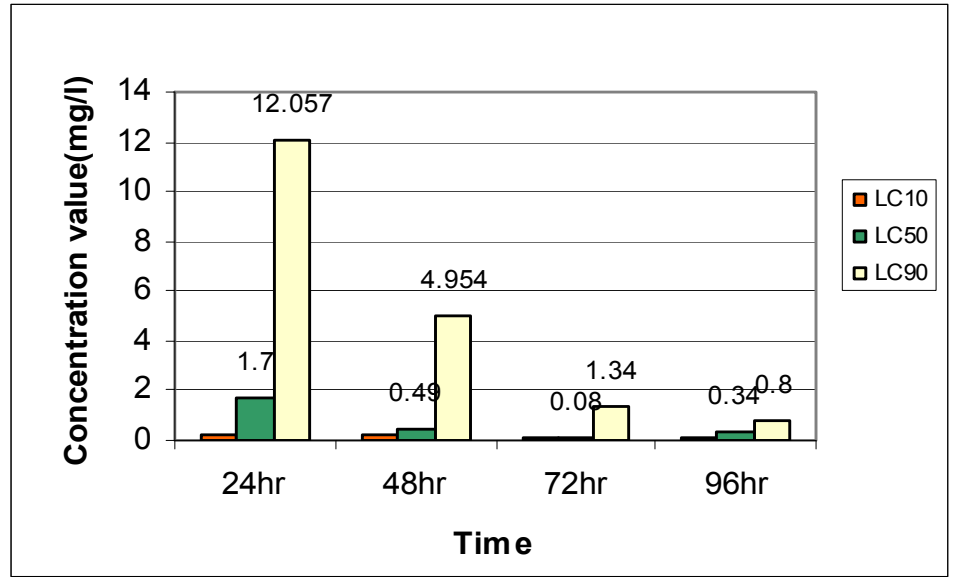

Figure 3: $\quad$ Influence of Diazinon on Rutilus frisii kutum.

Table 2: $\quad$ Effect of powder detergent on Rutilus frisii kutum.

\begin{tabular}{|c|c|c|c|c|c|}
\hline $\begin{array}{c}\text { Powder } \\
\text { detergent }\end{array}$ & $\begin{array}{c}\text { Lethal } \\
\text { concentration } \\
\text { (p.p.m) }\end{array}$ & $24 \mathrm{hr}$ & $48 \mathrm{hr}$ & $72 \mathrm{hr}$ & $96 \mathrm{hr}$ \\
\hline Rutilus & LC10 & 11.54 & 9.88 & 9.54 & 9.07 \\
frisii & LC50 & 14.67 & 12.95 & 12.65 & 12.24 \\
kutum & LC90 & 18.63 & 16.98 & 16.77 & 16.50 \\
\hline
\end{tabular}

\subsection{Influence of anionic detergents on Rutilus frisii kutum}

\subsubsection{Influence of powder detergent}

Concentrations of powder detergent in three experiments were from $10 \mathrm{mg} / 1$ to maximum $24 \mathrm{mg} / \mathrm{l}$ in comparison with the control. LC50-96hr was $12.24 \mathrm{mg} / 1$ [1]. The effective concentrations are summarized in Table 2 and Figure 4.

\subsubsection{Influence of liquid detergent}

Concentrations of liquid detergent in three experiments were from $5 \mathrm{mg} / \mathrm{l}$ to maximum $25 \mathrm{mg} / \mathrm{l}$ in comparison with the control. LC50-96hr was 8.93mg/l [1].

The effective concentrations are summarized in Table 3 and Figure 5. 


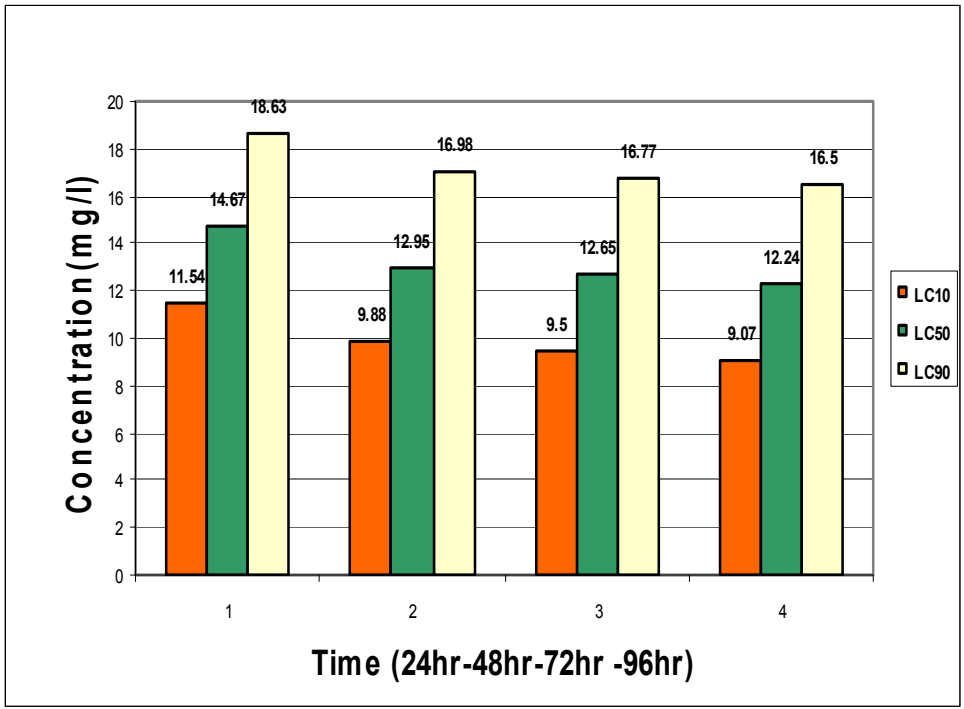

Figure 4: $\quad$ Influence of powder detergent on Rutilus frisii kutum.

Table 3: $\quad$ Effect of liquid detergent on Rutilus frisii kutum.

\begin{tabular}{|c|c|c|c|c|c|}
\hline $\begin{array}{c}\text { Liquid } \\
\text { detergent }\end{array}$ & $\begin{array}{c}\text { Lethal } \\
\text { concentration } \\
\text { (p.p.m) }\end{array}$ & $24 \mathrm{hr}$ & $48 \mathrm{hr}$ & $72 \mathrm{hr}$ & $96 \mathrm{hr}$ \\
\hline Rutilus frisii & LC10 & 7.80 & 6.05 & 7.24 & 6.59 \\
kutum & LC50 & 11.68 & 11.06 & 10.08 & 8.93 \\
& LC90 & 17.49 & 13.2 & 16.89 & 15.40 \\
\hline
\end{tabular}

\subsection{Influence of mixed pesticide and anionic detergents on Rutilus frisii $\mathrm{kutum}$}

\subsubsection{Mixed Diazinon and powder detergent}

According to three different experiments with various concentrations of mixed Diazinon and Powder Anionic Detergent (1-4mg/l) the mortality of fish increased especially in high concentration.LC50-96hr was $0.9 \mathrm{mg} / 1$ [1].

The results summarized in Table 4 and Figure 6.

\subsubsection{Mixed liquid detergent and Diazinon}

According to three different experiments with various concentration of mixed Diazinon and Liquid Anionic Detergent (4-20 mg/l) the mortality of fish increased especially in high concentration.LC50-96hr was $7.28 \mathrm{mg} / \mathrm{l}$. Mixed Diazinon and Powder Detergent with comparison of mixed Diazinon and Liquid Detergent was highly toxic[4].

The results summarized in Table 5 and Figure 7. 


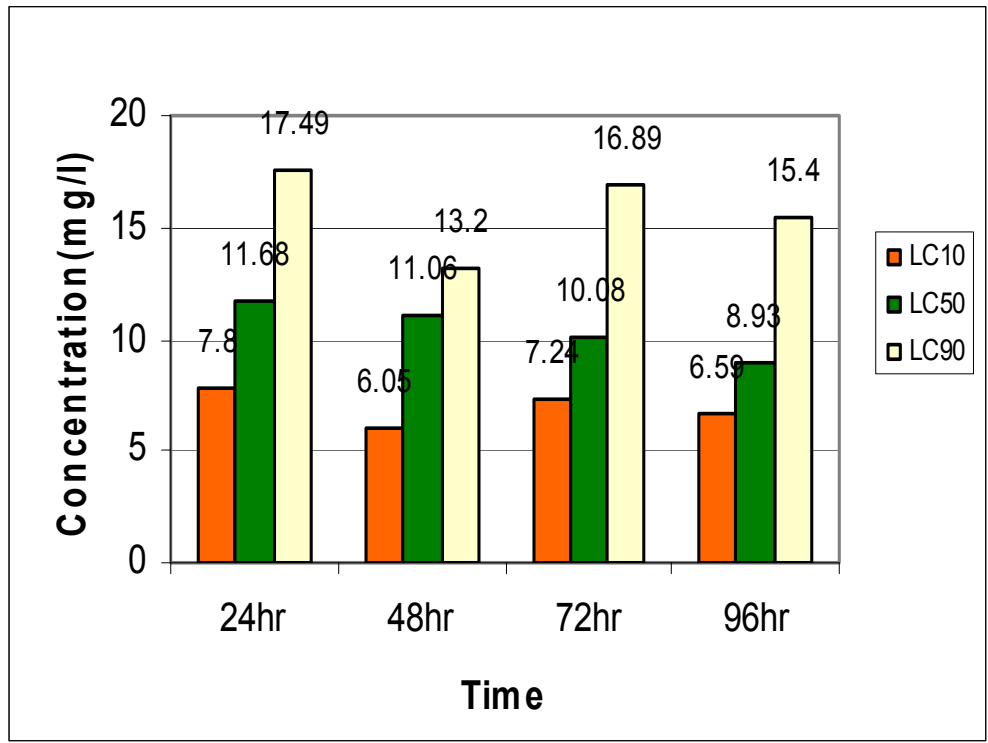

Figure 5: $\quad$ Influence of liquid detergent on Rutilus frisii kutum.

Table 4: $\quad$ Effect of mixed Diazinon and powder detergent on Rutilus frisii kutum.

\begin{tabular}{|c|c|c|c|c|c|}
\hline $\begin{array}{c}\text { Mixed Diazinon } \\
\text { \& powder } \\
\text { detergent }\end{array}$ & $\begin{array}{c}\text { Lethal } \\
\text { concentration } \\
\text { (p.p.m) }\end{array}$ & $24 \mathrm{hr}$ & $48 \mathrm{hr}$ & $72 \mathrm{hr}$ & $96 \mathrm{hr}$ \\
\hline Rutilus frisii & LC10 & 1.1553 & 1.0055 & 0.9446 & 0.5152 \\
kutum & LC50 & 1.7313 & 1.5677 & 1.4762 & 0.8970 \\
& LC90 & 2.5945 & 2.4444 & 2.3067 & 1.5615 \\
\hline
\end{tabular}

\section{Discussion}

This study indicates that effect of the pesticide and two detergents individually and together were different. The results showed that the LC50-96h was $0.34 \mathrm{mg} / \mathrm{l}$ for Diazinon. The LC50- $96 \mathrm{~h}$ for the fingerling of the same species under the effect of liquid and powder detergents, were 8.93 and $12.24 \mathrm{mg} / 1$ respectively. The LC50- $96 \mathrm{~h}$ under the effect of a Diazinon and liquid detergent and the mixture of Diazinon and powder detergent were 7.27 and $0.9 \mathrm{mg} / \mathrm{l}$ respectively was $0.34 \mathrm{mg} / \mathrm{l}$. According to the results, Diazinon was highly toxic, and it is LC50 - 96hr. It is clear that if Diazinon enters lagoons, water bloom will occur. In spring and summer, if the farmers are going to use pesticides, we have a serious problem with water bloom in fish ponds, especially in Anzali lagoon. 


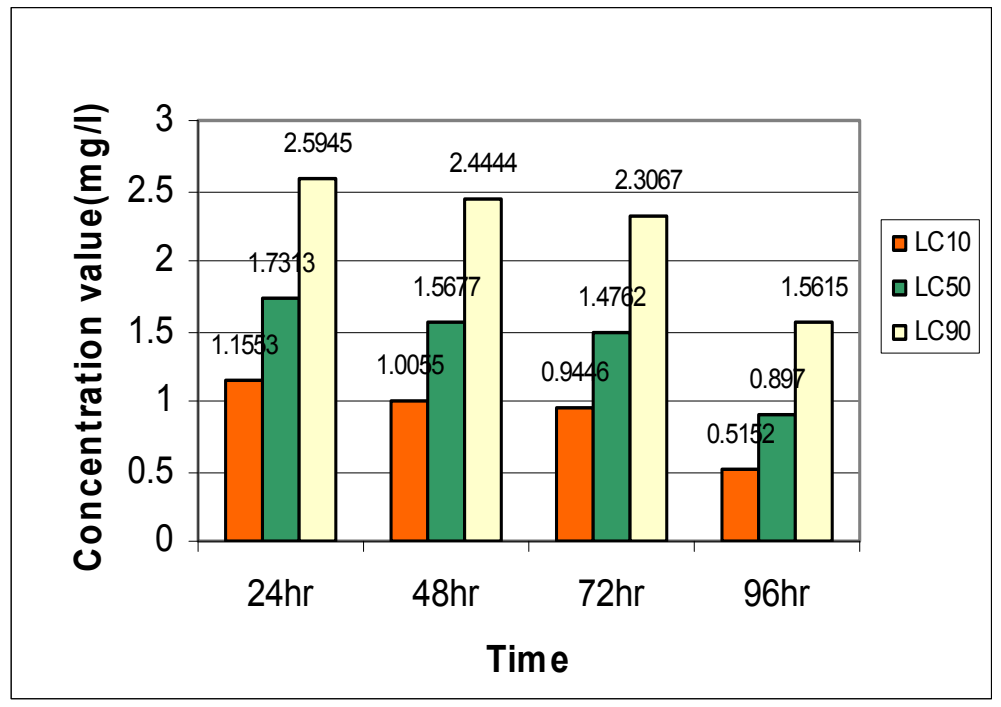

Figure 6: Influence of mixed Diazinon and powder detergent on Rutilus frisii kutum.

Table 5: Influence of mixed Diazinon and liquid detergent on Rutilus frisii kutum.

\begin{tabular}{|c|c|c|c|c|c|}
\hline $\begin{array}{c}\text { Mixed } \\
\text { Diazinon \& } \\
\text { liquid } \\
\text { detergent }\end{array}$ & $\begin{array}{c}\text { Lethal } \\
\text { concentration } \\
\text { (p.p.m) }\end{array}$ & $24 \mathrm{hr}$ & $48 \mathrm{hr}$ & $72 \mathrm{hr}$ & $96 \mathrm{hr}$ \\
\hline $\begin{array}{c}\text { Rutilus frisii } \\
\text { kutum }\end{array}$ & LC10 & 8.1995 & 7.4043 & 3.8637 & 3.6386 \\
& LC50 & 12.2831 & 10.9760 & 7.632 & 7.2759 \\
& LC90 & 18.4061 & 16.2708 & 16.009 & 13.703 \\
\hline
\end{tabular}

Thousands of fish may die annually and it is very dangerous for our aquatic ecosystems. Results showed that the most important reason for this problem is the mixture of detergents and pesticides. These mixtures are very toxic in general; it can be said that sometimes the concentration rate of detergents in a given ecosystem is less than the calculated LC50-96hr in a laboratory condition, but when the same concentration rate of detergent in ecosystem is mixed with another chemical material, it is very much possible that the percentage rate of mortality in fishes rises even higher. During the first 15 minutes of exposure, there was a rapid increase in the rhythm of opercula movements. Fish would also swim to the surface, gasping for air. A side from increased opercula rates, exposed fish also exhibited dark colorations on its dorsal side, along the entire 


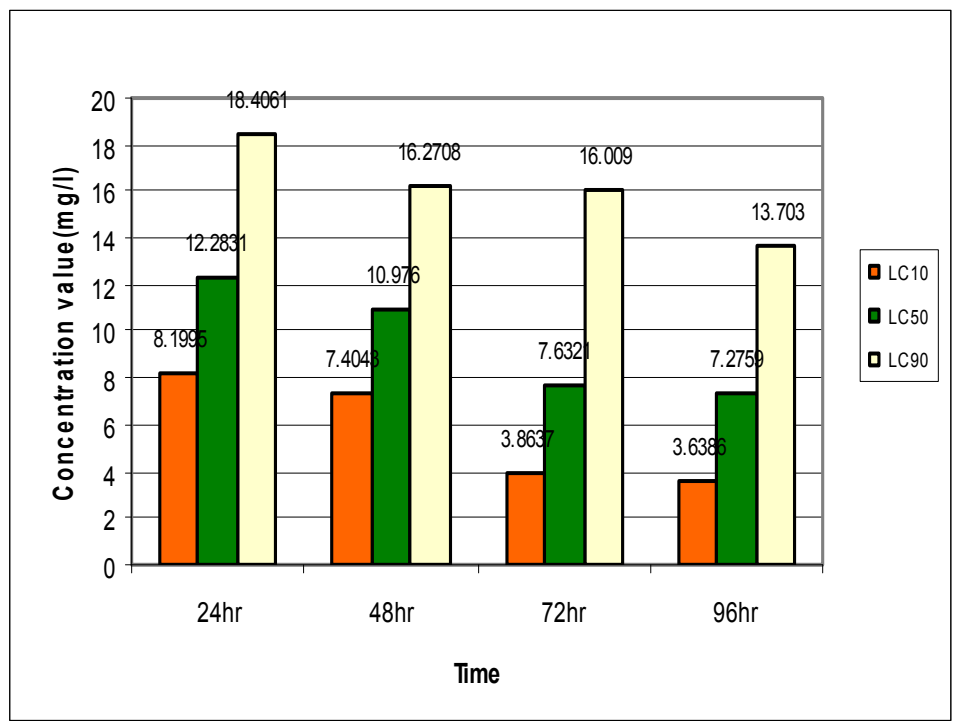

Figure 7: Influence of mixed Diazinon and liquid detergent on Rutilus frisii kutum.

dorsal length. Then the fish started to lose equilibrium, swimming in a vertical head down position, and setting on the bottom vertical side up. It would lay quietly, opercula movement becoming irregular with occasional bursts of frenzied swimming. Fish were also less sensitive to noise or movement. Death occurred within 3-9hr after the body darkening reaction started. This pigment modification of the dorsal surface of both investigated fish typically resembled fish under stress (Tamse and Gacutan [3]). Eyeballs become expanded and abnormal behaviour of fish increased with the increase of concentration of pesticide and detergents. In the all experiments dissolved oxygen in the aquatic medium of fish was always near to $80-100 \%$ of air saturation. The $\mathrm{pH}$ values have significantly decreased from 7.57 at concentration in aquatic medium to minimum 6.1.Hardness of water in the experiments was increased from 326 to $658 \mathrm{mg} / \mathrm{l}$. When test were finished (96hr), the control aquaria showed a very clean aquatic medium, but aquaria with pesticide and detergents individually and in mixed showed a very turbid medium. This turbidity was probably caused by the fish residues or the suspended compounds or its degradation products on water.

The objective of ecotoxicological laboratory tests and risk evaluation after all is the protection of the natural ecosystems and their inhabitants.

\section{References}

[1] OECD, Guidlines for testing of chemicals. Part C. Test Guidline.2031984a. 
[2] Tamim, M.Y., and D.L. Weigmann, Pesticides: a continuing dilemma. Journal water pollution control federation. Washington D.C. pp: 1199-1205, 1988.

[3] Tamse, C.T., and R.Q. Gacutan Acute toxicity of Nifurpirnol, a fish chemotherpeutant to milk fish (Chanos chanos) fingerlings pp: 346-350, 1994.

[4] T.R.C., OECD Guidelines for testing of chemicals section 2. Effects on biotic systems pp: 1-39, 1984.

[5] Young, A.L., Minimising the risk associated with Pesticide use. An overview in pesticides - minimizing the risks. N.N. Ragsdale and R.J. Kuhr (Eds). ACS Symp. Ser. 336. Amer. Chem. Soc. Washington. D.C. 1987. 